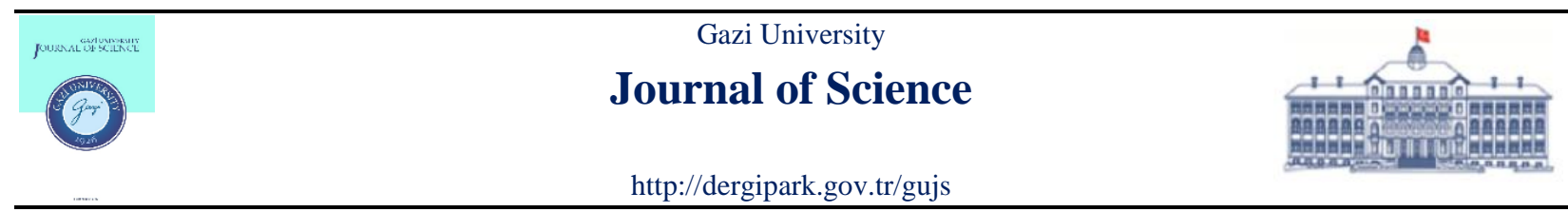

\title{
Sensitive and Selective Pathway of Total Antioxidant Capacity in Commercially Lemon, Watermelon and Mango-pineapple Cold Teas by Square Wave Adsorptive Stripping Voltammetry
}

\author{
Ersin DEMIR ${ }^{1, *}$ \\ ${ }^{I}$ Istanbul Okan University, Faculty of Engineering Department of Food Engineering, 34959, İstanbul, Turkey \\ Highlights \\ - It is possible to analyze the antioxidant capacity (AC) in tea samples by voltammetric pathway. \\ -A fast and simple voltammetric method was developed to evaluate AC. \\ -AC was deduced without any pretreatment application such as extraction, evaporation or separation.
}

\begin{tabular}{l} 
Article Info \\
\hline \\
Received: $30 / 11 / 2018$ \\
Accepted: $25 / 04 / 2019$ \\
Keywords \\
Antioxidant \\
Voltammetry \\
Tea \\
Electrochemistry
\end{tabular}

\begin{abstract}
The present work describes a convenient method for the sensitive and selective pathway of total antioxidant capacity (TAC) in lemon, watermelon and mango-pineapple cold teas by square wave adsorptive stripping voltammetry (SWAdSV) that is major electroanalytical methods on a carbon paste electrode. Anodic peak current of p-coumaric acid exhibited a well oxidation peak at 780 $\mathrm{mV}$ was used as a standard to evaluate TAC in tea samples. In addition, the very well-resolved and reproducible anodic processes, such as accumulation time, frequency, step potential etc. were optimized for the SWAdSV method. The potential applicability of the proposed SWAdSV was illustrated in commercial teas samples. SWAdSV proved to be a faster and easier method to calculate TAC compared to other conventional methods. Furthermore, total antioxidant amounts of commercially lemon, watermelon and mango-pineapple cold teas were found in optimum condition as equivalent to a concentration of $2050 \pm 15 \mathrm{mg} / \mathrm{L}, 705 \pm 10 \mathrm{mg} / \mathrm{L}$ and $808 \pm 14 \mathrm{mg} / \mathrm{L} \mathrm{p}$ coumaric acid ( $\mathrm{n}=3,95 \%$ confidence level), respectively.
\end{abstract}

\section{INTRODUCTION}

Nowadays-phenolic compounds, especially p-coumaric are abundant in not only food but also in beverages, so they became popular in industrial and scientific researches. The main reason why they are so popular in so many areas is that they have extremely significant influences on human body. Their antioxidant activity which is assembling of all redox pairs in the system is preventing oxidative degradation which is important for human health.

In other words, these compounds, even if they are present at low concentrations, can inhibit or decrease the harmful effects of reactive species on human health [1]. Furthermore, they can inhibit or activate special enzymes, control gene expressions, prevent lipid peroxidation and restrain risks of diseases like cancer [25]. Beside antioxidant activity, phenolic compounds also have chemo preventive and pharm therapeutic properties. These properties involve anti-inflammatory, anti-allergic, antimicrobial, anti-hemorrhagic, antiparasitic, antibacterial, antifungal, anticarcinogenic, antiviral and cardio protective actions [6,7].

Researches showed that there is a strong connection between the antioxidant compounds which similarity of structure for the phenolic agents and their electrochemical properties. The anodic peaks are responsible from good antioxidant activities where can be measure by electroanalytical methods [8]. These methods can divide into chromatographic and electrochemical applications that can perform characterization and quantification of phenolic compounds and their total content. Chromatographic methods are commonly 
used for qualitative measurements of polyphenols, they are fast, reliable and stable devices with a limit detection between 10-8 to 10-12 M [9-12]. However, the handling problems, solvent usage, samples pretreatment obligations, high cost and standard variations are limiting the high throughput analytical quality control $[13,14]$.

On the other hand, electrochemical methods are proved to be powerful device for the evaluation of electrochemical behavior of phenolic agents and their oxidation mechanisms performing total antioxidant capacity (TAC) compare with trolox equivalent antioxidant capacity (TEAC), ferric reducing antioxidant power (FRAP), 1,1-diphenyl-2-picrylhydrazyl (DPPH) and cupric reducing antioxidant capacity (CUPRAC) assay. These methods are fast, inexpensive and valuable alternative analytical technique that combines low operating and equipment costs and provides high precision and selectivity. Among electrochemical methods, using cyclic voltammetry (CV) [15], square wave voltammetry (SWV) [16] and differential pulse voltammetry (DPV)[17], have been the most trusted and commonly used electrochemical methods since one of the main objectives is to determine the TAC. Using different working electrodes are commonly preferred by researchers at voltammetric applications for various types of drug, agriculture substance analysis because of their easy sample preparation, quickness, sensitivity, cost effective instrumentation and possibility for the analysis of analyte in complex solution samples. [18-21]. All these electrochemical studies have improved to explain oxidation reaction of various natural polyphenols compounds and help us to understand, or to predict about how their chemical structure realized and deduce their ability to act as antioxidants [22]. Over the last decade, interest in antioxidant compounds has significantly attracted day by day due to different applications in biological, health, pharmaceutical and food industries [23-25]. The p-coumaric acid is one of the most important secondary metabolites with many physiological effects such as a strong antioxidant, anxiolytic, antimicrobial and immunoregulatory agent $[23,26]$. The determination of p-coumaric acid as a significantly antioxidant was mostly studied by high performance liquid chromatography (HPLC), thin layer chromatography, gas chromatography (GC) and spectrophotometric analysis [27,28]. However, there have been ongoing works on the determination of pcoumaric acid by the high selective and sensitive methods [29-32]. It needs a novel analytical technique which is high-throughput analysis, cost-effective, and easy application. Hence, due to the great advantages of the electrochemical methods over the last few years, it has received great interest [21;33-36].

In this study, electrochemical methods such as square wave adsorptive stripping voltammetry (SWAdSV) and cyclic voltammetry $(\mathrm{CV})$ were used on carbon paste electrode (CPE) for the investigation of behavior p-coumaric acid in detailed. The analysis of total antioxidant capacity (TAC) in the commercially cold tea samples by using possible oxidation peak current of p-coumaric acid using SWAdSV. The aim of this study is to improve a fully validated, fast and simple electrochemical method without any time pretreatment such as evaporation extraction and separation steps before to measure for the direct identification of TAC in natural samples.

\section{MATERIALS and METHODS}

\subsection{Instrumentation}

The square wave adsorptive stripping voltammetric (SWAdSV) and cyclic voltammetric (CV) studies were performed by using a CHI440B Electrochemical Analyzer (CH Instruments, Inc., USA). An electrochemical cell (BAS C3 stand) endowed with conventional three electrode systems with a carbon paste electrode (CPE) (as a working electrode) (BASi MF 2010; Ø $3 \mathrm{~mm}$, diameter), a platinum wire (as a counter) and $\mathrm{Ag} / \mathrm{AgCl}(3.0 \mathrm{M} \mathrm{KCl}$ ) electrode (as a reference) were used. For fabrication of CPE, carbon nanotube powder and water immiscible mineral oil was used at a mass ratio of $70 \%$ and $30 \%$, respectively. This mixture, made homogenous in a mortar, was plugged into the hollow part of the BASi MF 2010 electrode. Afterwards, the electrode surface was polished on a polishing cloth. The cleaning process, to remove the p-coumaric acid adhering on electrode surface and carried out by applying reverse potential at scan rate $1400 \mathrm{mV}$ to $0 \mathrm{mV}$ in cyclic voltammetric mode. The $\mathrm{pH}$ values were obtained by using digital a $\mathrm{pH}$ meter which has accuracy of \pm 0.05 (Mettler Toledo, OH, USA).

\subsection{Reagents and Solutions}


The analytical standard of p-coumaric acid $(\geq 98.0 \%)$ was obtained from Sigma-Aldrich. The stock solution of p-coumaric acid was prepared daily by dissolving it in ethanol (Sigma-Aldrich, 99.8\%) as a concentration of $500 \mathrm{ppm}$. All other chemicals were provided with an analytical grade and used without any purification step. $0.04 \mathrm{M}$ Britton-Robinson (B-R) solutions were used as a supporting electrolyte by mixing of $2.7 \mathrm{~mL}$ of orthophosphoric, $2.5 \mathrm{~g}$ of boric, and $2.3 \mathrm{~mL}$ of acetic acids in triple distilled water. $\mathrm{B}-\mathrm{R}$ buffer solutions were created from $\mathrm{pH} 2.0$ to 10.0 by adding the required amount of $5 \mathrm{M} \mathrm{NaOH}$ onto this triple acid mixture and monitoring with a $\mathrm{pH}$ meter. All daily prepared stock solutions were stored in a refrigerator at $4.0{ }^{\circ} \mathrm{C}$ and all electrochemical data were carried out at a comfortable ambient temperature $25 \pm 2{ }^{\circ} \mathrm{C}$.

\subsection{Food Samples Assay Procedure}

Different cold tea samples, lemon, watermelon and mango-pineapple, were purchased from a local market. Prior to measurement, all samples were mixed in the ultrasonic bath for 5 minutes. $0.1 \mathrm{~mL}$ of the real sample solution was directly placed into $10.0 \mathrm{~mL}$ of $\mathrm{pH} 5.0 \mathrm{~B}-\mathrm{R}$ buffer solution without any purification and pretreatment food samples. Then, the SWAdSV measurements from 0 to $800 \mathrm{mV}$ were obtained to determine the antioxidant capacity of food samples under optimum conditions (step potential $\left(\Delta \mathrm{E}_{\mathrm{s}}\right) 2 \mathrm{mV}$; frequency $(f) 250 \mathrm{~Hz}$; puls amplitude $(\Delta \mathrm{E}) 40 \mathrm{mV}$; accumulation potential $\left(\Delta \mathrm{E}_{\text {acc }}\right) 100 \mathrm{mV}$; accumulation time $\left(\Delta \mathrm{t}_{\mathrm{acc}}\right) 30 \mathrm{~s}$ and $\mathrm{pH} 5.0 \mathrm{~B}-\mathrm{R}$ buffer solutions. The voltammetric measurements where repeated three times and the validation parameters were investigated to support accuracy and precision of method for the all food samples.

\section{RESULTS and DISCUSSION}

\subsection{Electrochemical Behavior of p-Coumaric Acid}

In order to evaluate electrochemical behavior of the p-coumaric acid and characterized substances that transfer from solution to electrode surface in which adsorption or a diffusion-controlled process, cyclic voltammograms taken at different scan rate from $10 \mathrm{~s}^{-1}$ to $500 \mathrm{~s}^{-1}$ in $\mathrm{pH} 5.0$ buffer solution. In the anodic potential scans, a well-shaped anodic peak of p-coumaric acid was observed nearly at $+800 \mathrm{mV}$ but no peak was obtained in the potential scans of the cathodic direction as a cathodic peak. In addition, when the scan rate increased from 10 to $500 \mathrm{mV} / \mathrm{s}$, peak potential of p-coumaric acid shifted towards less positive potential (Equation 1). These data demonstrated that, p-coumaric acid has irreversible electrochemical properties on carbon paste electrode.

In order to understand whether substance are transporting by diffusion or adsorption process, the peak current values of p-coumaric acid were investigated at different scanning rates. According to Laviron's view, if the slope values of logarithmic scan rate-the logarithmic peak current are 0.5 and 1.0, substance transport is accepted by diffusion and absorption process, respectively [37]. The logarithm of the scanning rate against the peak current $(\log v)$ was calculated and the slope of logarithm of the scanning rate against the peak current was found as 1.12 (Equation 2). This value can be accepted to the theoretical value of 1, which also suggests that adsorption controlled in electrode reaction. Moreover, the anodic peak was shifted in less positive potential with the increments of scan rate from 10 to $500 \mathrm{mV} / \mathrm{s}(\mathrm{n}=8)$.

$\log \operatorname{Ep}(V)=-0.21 \log v(V / s)+0.74, r=0.9914, n=8$

$\log \operatorname{Ip}(\mu \mathrm{A})=1.12 \log \mathrm{v}(\mathrm{V} / \mathrm{s})+0.57, r=0.9676, \mathrm{n}=8$

\subsection{The Influence of pH}

In the electrochemical studies, supporting electrolyte is one of the most important parameters due to the effects on peak potential, current intensity and kinetics of the electron transfer process. Therefore, the effects of supporting electrolyte were investigated on the electro-oxidation signal of p-coumaric acid at various $\mathrm{pH}$ values by carbon paste electrode. In order to analyze the $\mathrm{pH}$ effect, SWAdS voltammograms were taken in the Britton-Robinson (B-R) supporting electrolyte solution between $\mathrm{pH} 2.0$ and $\mathrm{pH} 7.0$ for the $5 \mathrm{mg} / \mathrm{L}$ p-coumaric acid (Figure 1). SWS experiments that the highest signal performed in weak acidic 
media as $\mathrm{pH} 5.0 \mathrm{~B}-\mathrm{R}$ buffer was found to be dependent on the below $\mathrm{pH} \leq 7.0$ buffer solutions. Moreover, the oxidation peak potential of p-coumaric acid gradually decreased more negative potential from $0.83 \mathrm{~V}$ to $0.57 \mathrm{~V}$ by $-53.52 \mathrm{mV}$ per unit $\mathrm{pH}$ changes, while the $\mathrm{pH}$ value increased from 2.0 to 7.0 (Figure 2, Equation 3). This is the evidence that hydrogen ions contains in the electrochemical oxidation process for the p-coumaric acid. The maximum peak current and well-shaped was formed in $\mathrm{pH}$ 5.0. So that $\mathrm{pH}$ 5.0 B$\mathrm{R}$ buffer solution was chosen as an optimum supporting electrolyte to determine p-coumaric acid.

$\mathrm{Ep}(\mathrm{mV})=-53.52 \mathrm{pH}+945.87(\mathrm{mV}), \mathrm{r}=0.9974$

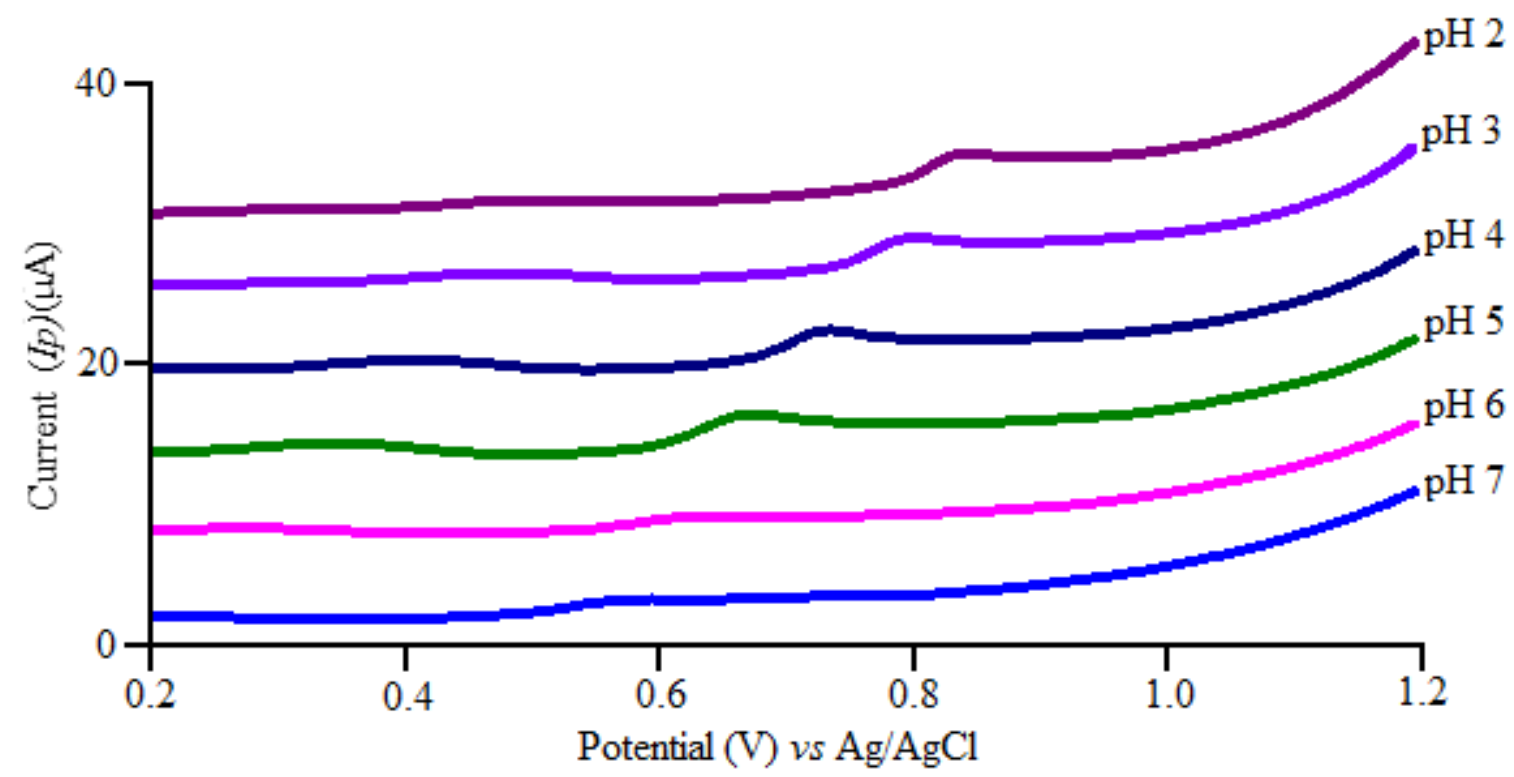

Figure 1. SWAdSV voltammograms of $5 \mathrm{mg} / \mathrm{L}$ p-coumaric acid at various $\mathrm{pH}$ on carbon paste electrode

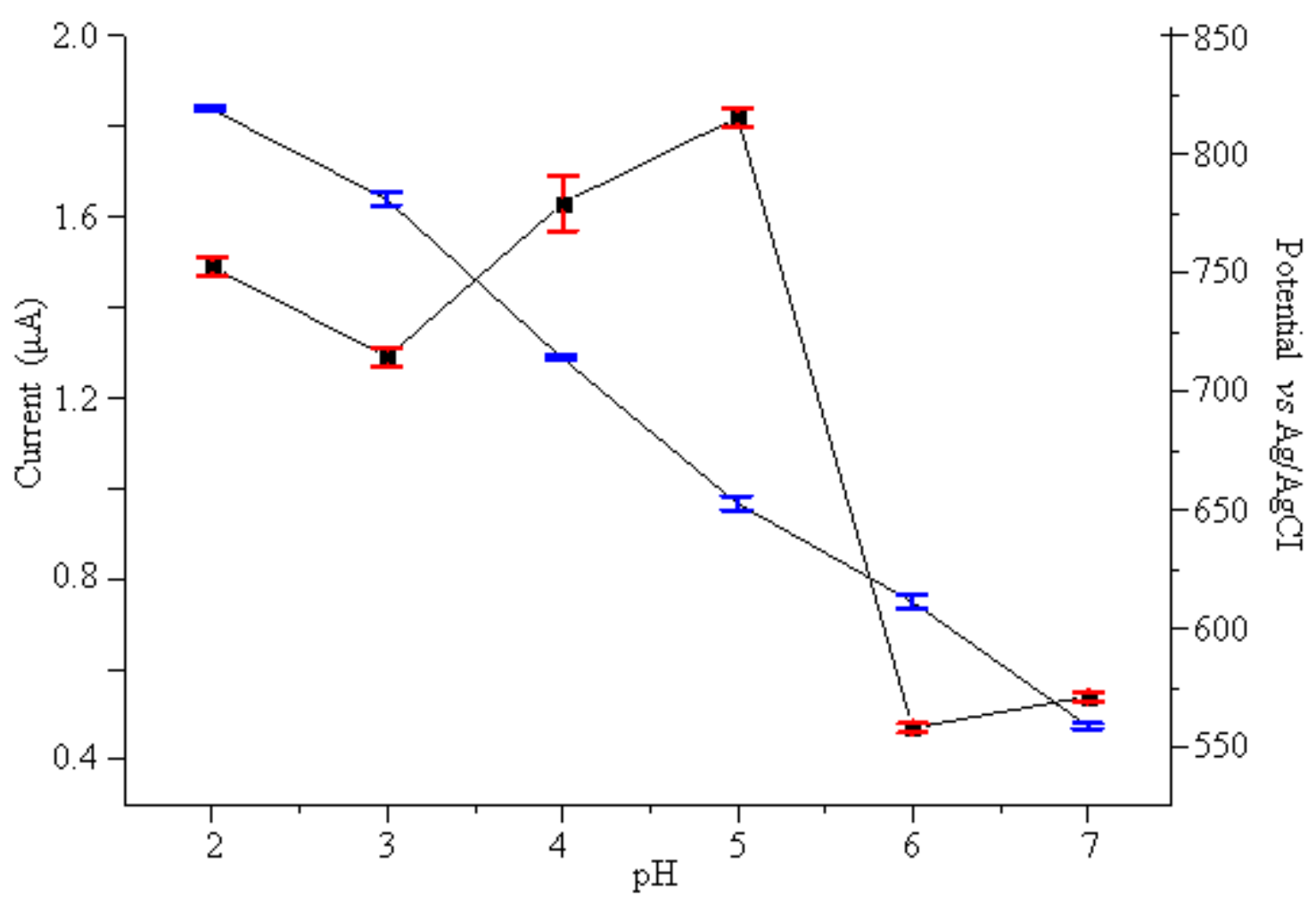


Figure 2. Influence of $\mathrm{pH}$ for the $5 \mathrm{mg} / \mathrm{L}$ of p-coumaric acid from $\mathrm{pH} 2.0$ to $\mathrm{pH} 7.0$ on carbon paste electrode ( I ; peak potential, - ' peak current $n=3$ )

\subsection{Optimization SWAdSV Parameters}

The response of peak potential and current intensity by square wave stripping voltammetric depends markedly on electrochemical analyzer condition. The optimum analyzer conditions in stripping mode such as accumulation potential, accumulation time, amplitude, frequency and step potential were studied to obtain a more sensitive peak current for $5 \mathrm{mg} / \mathrm{L}$ of p-coumaric acid (Figure 3 ).

The effect of step potential was investigated by varying step potentials from $1 \mathrm{mV}$ to $5 \mathrm{mV}$ (Figure $3 \mathrm{~A}$ ). The peak current increased up to $2 \mathrm{mV}$ and then it suddenly decreased to lower peak currents at different step potential scans. Due to the maximum peak current and well-shaped was performed at $2 \mathrm{mV}$ the $2 \mathrm{mV}$ was taken as the optimum step potential for the subsequent measurements. The influence of pulse amplitude was also investigated at various amplitudes from $10 \mathrm{mV}$ to $60 \mathrm{mV}$ (Figure 3B). The oxidation peak signal increased to $40 \mathrm{mV}$ however, peak signal was not increased significantly in the subsequent pulse amplitudes. So that $40 \mathrm{mV}$ was chosen as optimum pulse amplitude. In addition, accumulation potential and accumulation time, which are the most effective parameters for peak current, were researched. SWAdS voltammograms were taken from $0 \mathrm{mV}$ to $400 \mathrm{mV}$ and from $10 \mathrm{~s}$ to $60 \mathrm{~s}$ for the accumulation potential and time, respectively. The peak signal of p-coumaric acid increased until $100 \mathrm{mV}$ accumulation potential with $30 \mathrm{~s}$ deposition times (Figure 3C). Oxidation peak was decreased after $100 \mathrm{mV}$ and also the peak signal remained fixed by increased accumulation potential. The peak current was increased up to 30s and after 30 s it decreased sharply because of the substance is completely covered by the electrode surface (Figure 3D). The last optimized parameter frequency was studied between 25 and $600 \mathrm{~Hz}$ (Figure 3E). The oxidation peak signal increased regularly up to $600 \mathrm{~Hz}$. However, peak shapes of p-coumaric's voltamograms were not obtained properly after $250 \mathrm{~Hz}$. Therefore, the optimum frequency was selected as a $250 \mathrm{~Hz}$ according to well-obtained peak shape. The best peak definition of p-coumaric acid was obtained under the optimum condition when using $2 \mathrm{mV}$ step potential, $40 \mathrm{mV}$ puls amplitude, $100 \mathrm{mV}$ accumulation potential, $30 \mathrm{~s}$ accumulation time and $250 \mathrm{~Hz}$ frequency for the $5 \mathrm{mg} / \mathrm{L} \mathrm{p}$-coumaric acid in $\mathrm{pH} 5.0 \mathrm{~B}-\mathrm{R}$ buffer solution. 


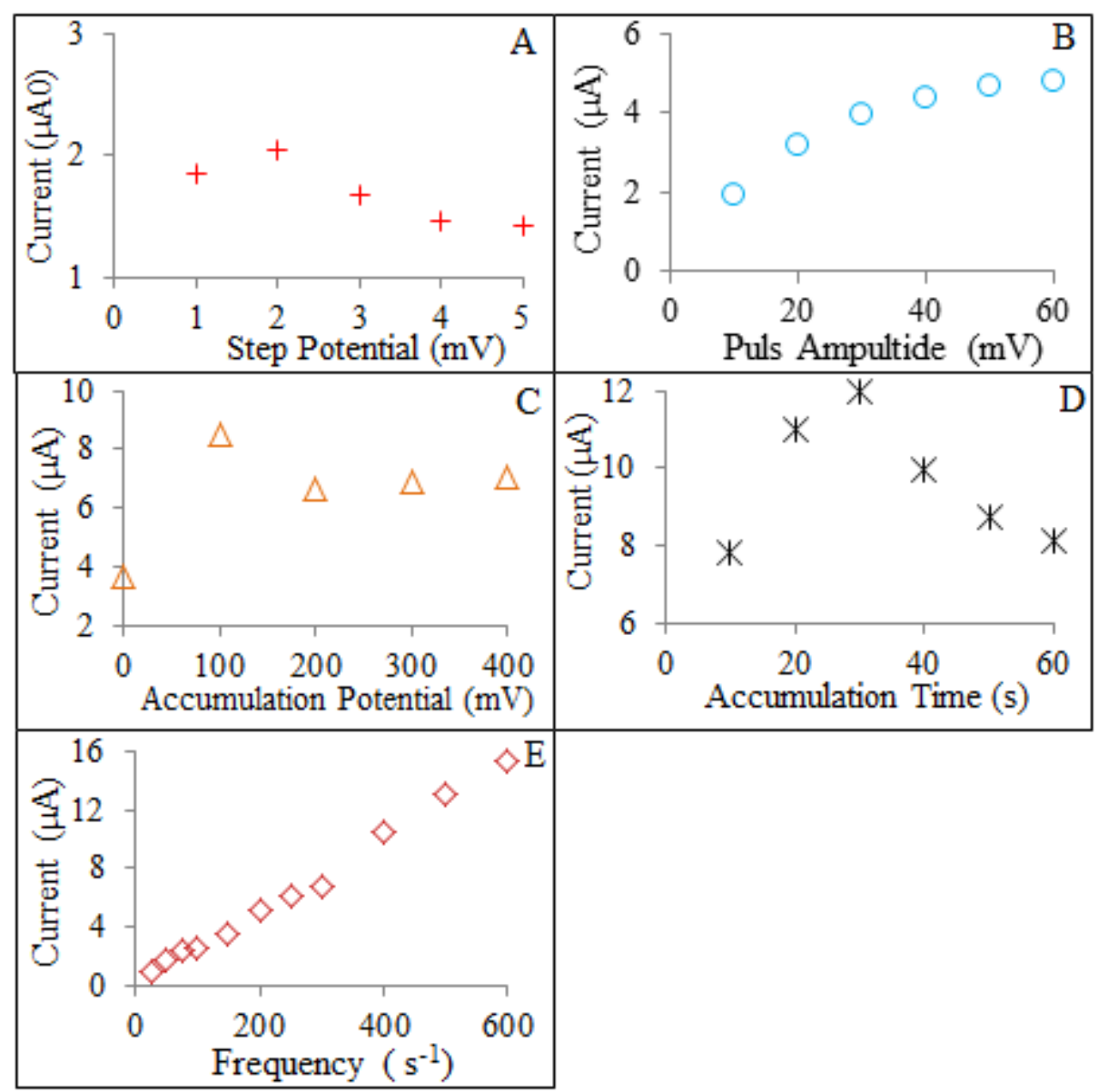

Figure 3. The optimization parameters for $5 \mathrm{mg} / \mathrm{L}$ of p-coumaric acid on the carbon paste electrode at $\mathrm{pH}$ of $5.0 B-R$ buffer solutions

\subsection{Quantitative Evaluation of p-Coumaric Acid}

The calibration graph was obtained from p-coumaric acid stock solution by using SWAdSV on the CPE in $10 \mathrm{~mL}$ pH 5.0 Britton-Robinson buffer solutions according to standard addition method (Figure 4). The anodic response on carbon paste electrode was performed towards the exactly concentration of p-coumaric acids by SWAdSV under the optimized condition (Equation 4). The calibration graph was drawn according to these responses to find linear working range. Moreover, the limit of detection (LOD) $=$ " $3 \mathrm{~s} / \mathrm{m}$ " and the limit of quantification (LOQ) $=$ " $10 \mathrm{~s} / \mathrm{m}$ " equations, where " $\mathrm{m}$ " is the slope of $\mathrm{p}$-coumaric acid and "s" is the standard deviation of intercept, were used to calculated LOD and LOQ [38]. As a result, the linear working range was found as $0.15-20 \mathrm{mg} / \mathrm{L}$. In addition, LOD and LOQ were calculated 0.11 and 0.37 $\mathrm{mg} / \mathrm{L}$. 


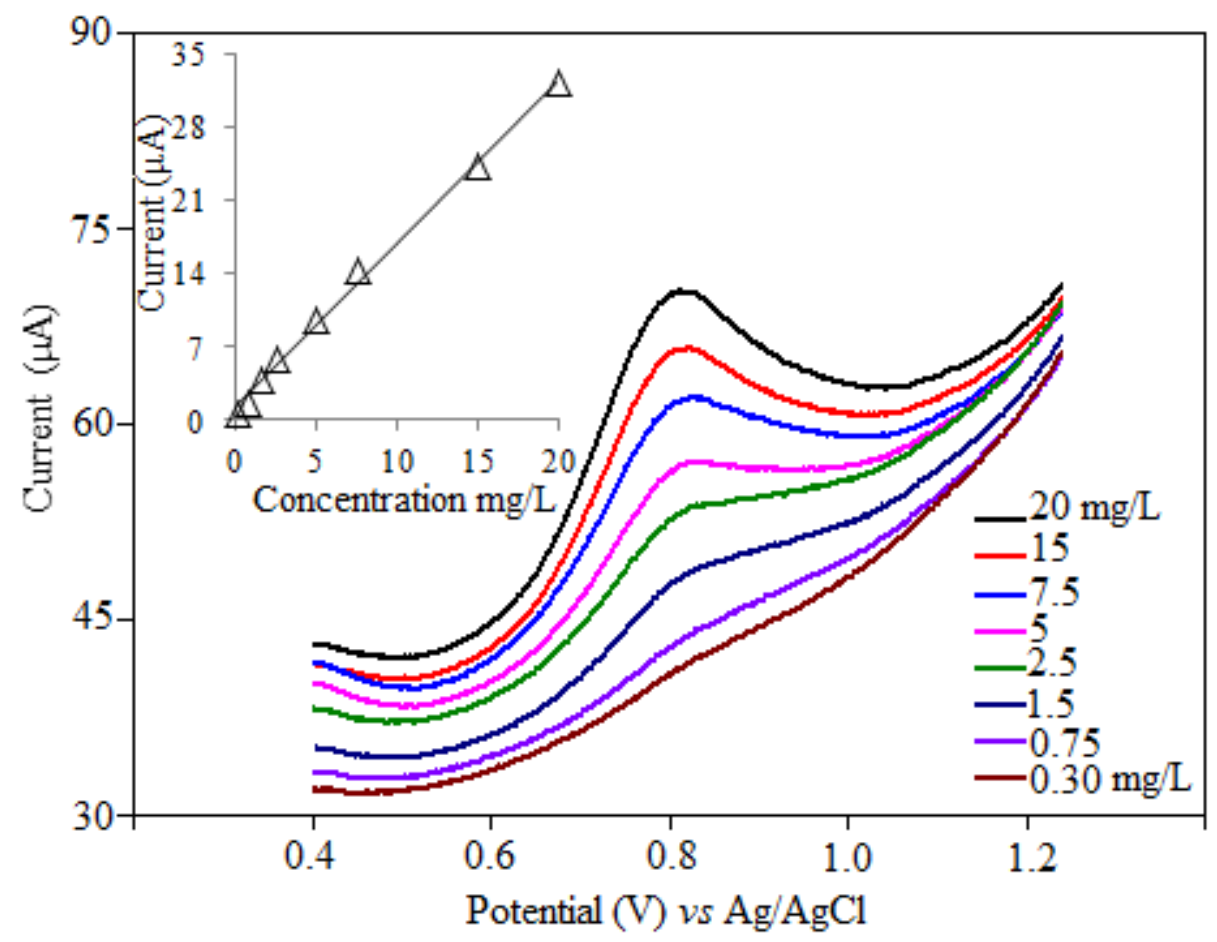

Figure 4. SWAdSV voltammograms and calibration graph for the p-coumaric on carbon paste electrode $\left(\Delta E_{s}=2 \mathrm{mV} ; f=250 \mathrm{~Hz} ; \Delta E=40 \mathrm{mV} ; \Delta E_{a c c}=100 \mathrm{mV}, \Delta t_{a c c}=30 \mathrm{~s}, \mathrm{pH} 5.0 \mathrm{~B}-\mathrm{R}\right.$ buffer solutions $)$

$\operatorname{Ip}(\mu \mathrm{A})=1.551 \mathrm{C}(\mathrm{mg} / \mathrm{L})+1.335 \mathrm{r}=0.9956$

Table 1. Validation parameters for evaluation of p-coumaric acid by SWAdSV on carbon paste electrode

\begin{tabular}{lc}
\hline Peak potential $\left(\mathrm{E}_{\mathrm{p}}\right) v s . \mathrm{Ag} / \mathrm{AgCl}(\mathrm{mV})$ & +780 \\
\hline Linear working range $(\mathrm{mg} / \mathrm{L})$ & $0.15-20.0$ \\
Slope $(\mu \mathrm{A} \mathrm{L} / \mu \mathrm{g}) \pm$ standard deviation $(\mathrm{s})$ & $1.551 \pm 0.015$ \\
Intercept $(\mu \mathrm{A}) \pm$ standard deviation $(\mathrm{s})$ & $1.335 \pm 0.059$ \\
$\mathrm{LOD}(\mu \mathrm{g} / \mathrm{L})$ & 0.11 \\
$\mathrm{LOQ}(\mu \mathrm{g} / \mathrm{L})$ & 0.37 \\
Correlation coefficient & 0.9956 \\
Reproducibility of the peak current* $(\mathrm{RSD} \%)$ & 3.59 \\
Reproducibility of the peak potential* $(\mathrm{RSD} \%)$ & 1.01 \\
\hline
\end{tabular}

Reproducibility value for the peak current singal and peak potential was calculated in seven different measurements for $0.4 \mathrm{mg} / \mathrm{L} \mathrm{p}$-coumaric acid and was found with a relative standard deviation (RSD\%) of $3.59 \%$ and $1.01 \%$, respectively. Accordingly, validation parameters were summarized in the Table 1 for the p-coumaric acid, which reflects that electrochemical method exhibits reasonably precision, accuracy, and reproducibility.

Liu et al. (2006) in their study for the analysis of p-coumaric acid in the rat plasma by using the HPLC-UV method, they calculated limit of quantification (LOQ) value as $0.02 \mathrm{mg} / \mathrm{L}$ [39]. Zhang et al. (2019) recommended a new HPLC-MS method for the analysis 17 types of phenolic acids for the vegetables consumed in China. In order to evaluation of p-coumaric acid in vegetables, they found the limit of determination for this target agent was found $0.012 \mathrm{mg} / \mathrm{L}$ [40]. Silina et al. (2016) used a validated and rapid technique RP-HPLC method to detect p-coumaric acid in real sample like methanolic extracts of Durva Grass [41]. They found the LOD and LOQ values as $0.302 \mu \mathrm{g}$ and $0.99 \mu \mathrm{g}$, respectively. According to the LOD and LOQ results obtained by traditional analytical methods such as HPLC-UV, RP-HPLC and 
HPLC-MS, the developed SWAdSV method on carbon paste electrode, as found the LOD is $0.11 \mu \mathrm{g} / \mathrm{L}$ and LOQ is $0.37 \mu \mathrm{g} / \mathrm{L}$, is quite interesting and competent.

\subsection{Electrochemical Pathway of p-Coumaric Acid}

In order to show electrochemical pathway of p-coumaric acid, number of transfer electrons which is electrode reaction in oxidation process was calculated. For an irreversible oxidation-reduction process, Ep is described by the following equation which is recommended with Laviron [42].

$$
E p=E^{0 \prime}-\frac{2.303 R T}{\alpha \mathrm{nF}} \log \frac{R T \mathrm{k}^{o}}{\alpha \mathrm{nF}}+\frac{2.303 R T}{\alpha \mathrm{nF}} \log v
$$

where $\mathrm{E}^{0 \prime}, \mathrm{R}, \alpha, \mathrm{T}, \mathrm{n}, \mathrm{k}^{0}, \mathrm{~F}$, and $v$ are formal potential, gas constant, transfer coefficient, temperature, number of transferred electrons, standard heterogeneous rate constant, Faraday constant and potential scan rate, respectively. According to this equation, the value of $\alpha$ n was found from the slope of Ep on $\log v$ plot. The slope of Ep on $\log v$ was calculated as $0.21 \mathrm{~V}$. When the all know values are written in the above equations, $\alpha$ is found to be 0.28 . For the irreversible processes, $\alpha$ value can be taken as 0.5 in electrode reaction and consequently number of transferred electrons (n) was evaluated as 0.56 . This value can be regarded as 1 integer in oxidation reaction of p-coumaric acid. In addition, to evaluate whether p-coumaric acid contains a proton $\left(\mathrm{H}^{+}\right)$in the electrode reaction, the effect of $\delta \mathrm{Ep} / \delta \mathrm{pH}$ is examined. In the $\mathrm{pH}$ study (Figure 1), a shift of $-53.52 \mathrm{mV}$ occurred in the oxidation peak of coumaric acid against the change by per unit in $\mathrm{pH}$. It is proved that proton $\left(\mathrm{H}^{+}\right)$contains in the electro-oxidation reaction due to the shift of peak potential in negative regions for the oxidation of the p-coumaric acid by the increasing $\mathrm{pH}$ units. Also, according to the literature review, it was proposed that the anodic peak of the p-coumaric acid can be $-\mathrm{OH}$ group on benzene ring [43]. The results were found to be compatible with the proposed mechanisms for $\mathrm{p}$ coumaric.

\subsection{Selectivity Study}

In the view of possible application for the p-coumaric acid as a standard antioxidant agent in natural food samples, effects of the interference substances were examined. Hence, $\mathrm{Ca}^{2+}, \mathrm{Mg}^{2+}, \mathrm{Na}^{+}$, methoxyflavone, caffeic acid, gallic acid and rutin were studied by means of recovery tests (Figure 5). The percentage recovery was made by comparing the peak current of coumaric acid in the presence and also absence of interference species at $\mathrm{pH}$ 5.0 B-R buffer solution on CPE. Moreover, the tolerance limit of inference substance was evaluated as the concentration ratio of foreign electro-active antioxidant substances/pcoumaric acid at $1: 1$ and $1: 2$ by mass causing less than $10.0 \%$ relative error on peak intensity. They did not show any interference effects due to they could not give any peaks near the peak potential of the pcoumaric acid at $+0.8 \mathrm{~V}$. In addition, the influence of some cationic species like $\mathrm{Ca}^{2+}, \mathrm{Mg}^{2+}$, and $\mathrm{Na}^{+}$that found commonly in food and environment samples were also studied. They displayed no interfering effects due to none of them is electro active in the potential of oxidation of coumaric acid. The recovery of pcoumaric acid in the presence of $\mathrm{Ca}^{2+}, \mathrm{Mg}^{2+}$, and $\mathrm{Na}^{+}$with the mass ratios of 1:10, and 1:20 were extended from $95.25 \%$ to $103.03 \%$. Since there is no serious effect of anodic peak intensity of p-coumaric acid on any interference substances, this electrochemical method can be considered to be selective. 


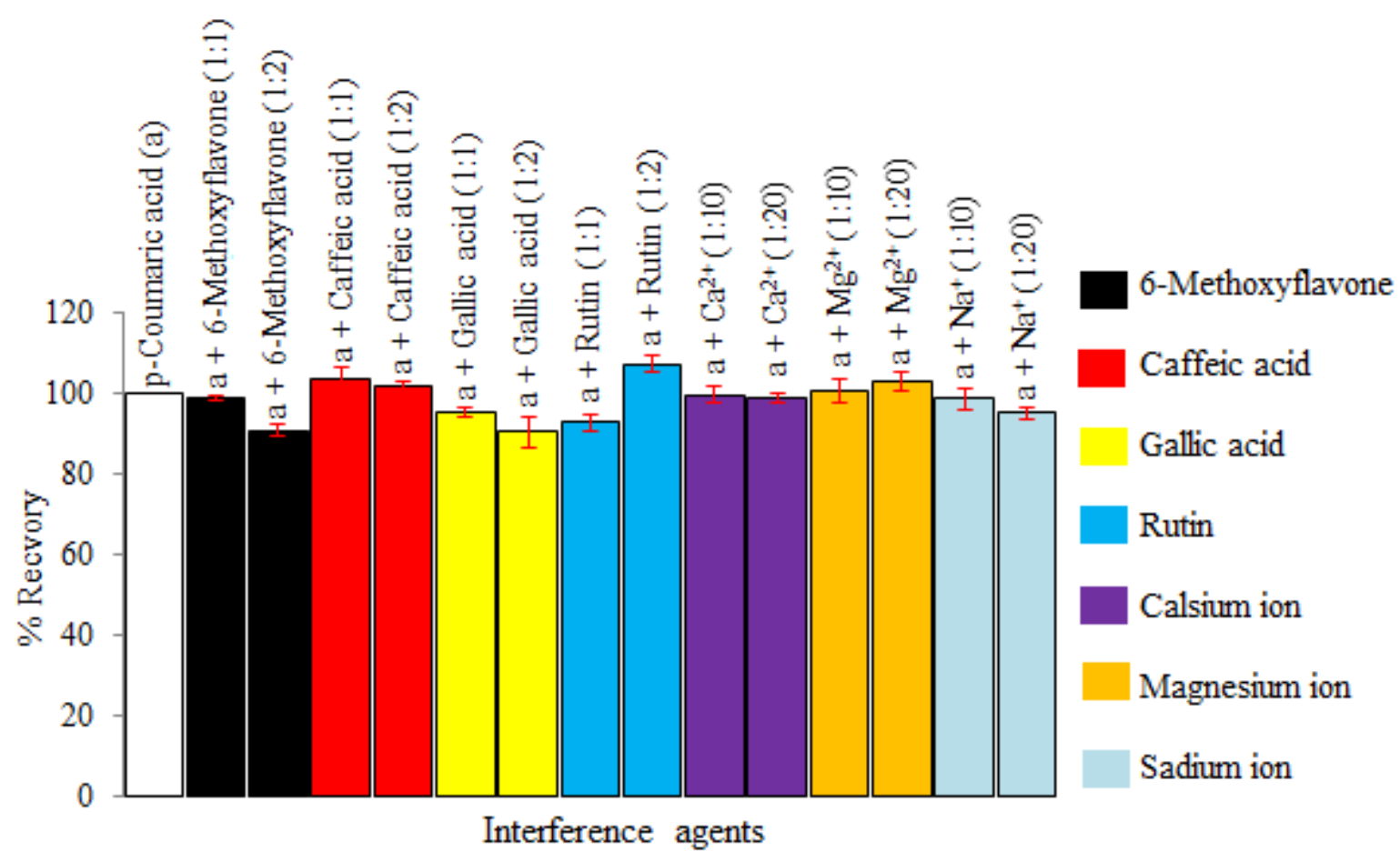

Figure 5. \% Recovery of p-coumaric acid in presence some interference agents

\subsection{The Evaluation of Total Antioxidant Capacity (TAC) in Commercial Cold Teas}

In order to show the analytical applicability of the developed SWAdSV method for the directly determination of total antioxidant, some experiments were carried out in in commercially lemon, watermelon and mango-pineapple cold teas (Figure 6). A standard addition method was used by using pcoumaric acid in the cold tea samples without any purification and pretreatment for the determination of TAC. The cold tea samples were mixed in the ultrasonic bath for 5 minutes prior to analysis. All samples were analyzed with three replicates measurements, and the RSD were calculated lower than $1.73 \%$, revealing the excellent precision. Furthermore, total antioxidant amounts of commercially lemon, watermelon and mango-pineapple cold teas for the $1 \mathrm{~L}$ natural samples were found as equivalent to a concentration of $2050 \pm 15 \mathrm{mg} / \mathrm{L}, 705 \pm 10 \mathrm{mg} / \mathrm{L}$ and $808 \pm 14 \mathrm{mg} / \mathrm{L}$ p-coumaric acid $(\mathrm{n}=3,95 \%$ confidence level), respectively. The data presented in Table 2 and Figure 6 demonstrated that proposed electrochemical methods can be efficiency applied for evaluate the total antioxidant in natural samples. 


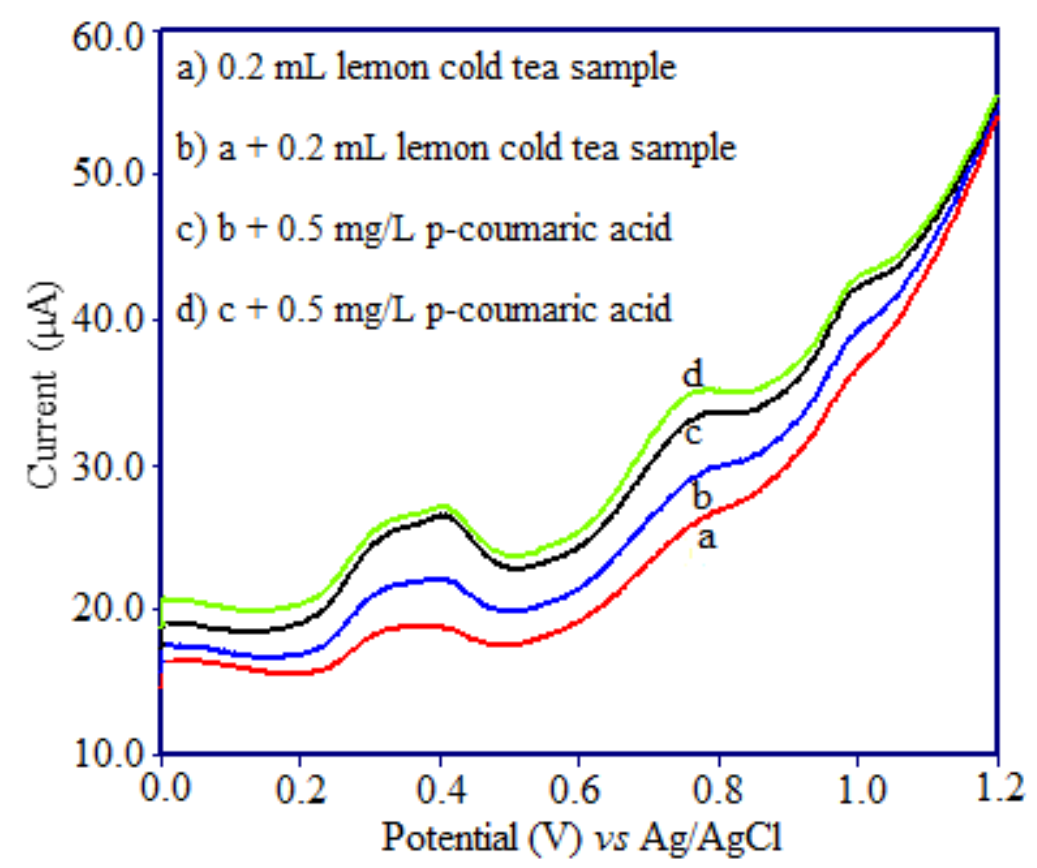

Figure 6. Electrochemical determination pathway of total antioxidant capacity for the commercially lemon tea by SWAdSV on carbon paste electrode a) $0.2 \mathrm{~mL}$ lemon cold tea sample b) a $+0.2 \mathrm{~mL}$ lemon cold tea sample c) $b+0.5 \mathrm{mg} / \mathrm{L}$ p-coumaric acid d) $c+0.5 \mathrm{mg} / \mathrm{L}$ p-coumaric acid $\left(\Delta E_{s}=2 \mathrm{mV} ; f=250 \mathrm{~Hz} ; \Delta E=\right.$ $40 \mathrm{mV} ; \Delta E_{a c c}=100 \mathrm{mV} ; \Delta t_{a c c}=30 \mathrm{~s}, \mathrm{pH} 5.0 \mathrm{~B}-\mathrm{R}$ buffer solutions)

Table 2. The determination of total antioxidant capacity for the commercially cold tea samples by SWAdSV on carbon paste electrode

\begin{tabular}{lccc}
\hline $\begin{array}{l}\text { Sample } \\
\text { (Commercially cold tea, 1L) }\end{array}$ & $\begin{array}{c}\text { Total antioxidant capacity } \\
\text { (Equivalent p-coumaric acid)* }\end{array}$ & \% RSD & $\begin{array}{c}\text { \% Recovery } \\
(1 \mathrm{mg} / \mathrm{L} \text { p-coumaric acid)* }\end{array}$ \\
\hline Lemon & $2050 \pm 15 \mathrm{mg} / \mathrm{L}$ & 0.73 & $94.75 \pm 3.97$ \\
Watermelon & $808 \pm 14 \mathrm{mg} / \mathrm{L}$ & 1.73 & $96.83 \pm 2.18$ \\
Mango-pineapple & $705 \pm 10 \mathrm{mg} / \mathrm{L}$ & 1.42 & $94.31 \pm 2.92$
\end{tabular}

$* \mathrm{n}=3$ repeated measurements

\section{CONCLUSION}

The sensitive and selective voltammetric method was fabricated for the analysis of total antioxidant capacity (TAC) in cold tea samples by square wave voltammetry adsorptive stripping mode (SWAdSV) on carbon paste electrode. Optimum conditions for the SWAdSV such as accumulation time, frequency, step potential etc. were optimized to evaluate TAC. Moreover, SWAdSV can be used to directly evaluate qualitative and quantitative analysis for phenol compounds in presence interferences substances such as 6methoxyflavone, caffeic acid, gallic acid and rutin. So that, it can be suggested that electrochemical method is the most suitable candidate due to simplicity, accuracy, selectivity and the reliability of p-coumaric acid in complex food samples. In addition, it is can be compared with chromatography methods due to low detection limit values. Therefore, trace amounts of antioxidant capacity in food sample can be determined by SWAdSV without any pre-processing. Consequently, SWAdSV directly applied to deduce TAC in cold tea samples without purification.

\section{ACKNOWLEDGMENTS}

I would like to thank Dr. Garbis Atam AKCEOGLU for his help with preparation of the manuscript. 


\section{CONFLICTS OF INTEREST}

No conflict of interest was declared by the author.

\section{REFERENCES}

[1] Lugonja, N.M., Stanković, D.M., Spasić, S.D., Roglić, G.M., Manojlović, D.D. and Vrvić, M.M. "Comparative electrochemical determination of total antioxidant activity in infant formula with breast milk", Food Anal. Methods, 7: 337-344, (2014).

[2] Abdali, D., Samson, S.E. and Grover, A.K. "How effective are antioxidant supplements in obesity and diabetes?', Med. Princ. Pract., 24: 201-215, (2015).

[3] Dias, T.R., Alves, M.G., Tomas, G.D., Socorro, S., Silva, B.M. and Oliveira, P.F., "White tea as a promising antioxidant medium additive for sperm storage at room temperature: a comparative study with green tea", J. Agric. Food Chem., 62: 608-617, (2014).

[4] Jurado-Coronel, J.C., Ávila-Rodriguez, M., Echeverria, V., Hidalgo, O.A., Gonzalez, J., Aliev, G. and Barreto, G.E., "Implication of green tea as a possible therapeutic approach for parkinson disease", CNS Neurol. Disord. Drug Targets, 15: 292-300, (2016).

[5] Đudarić, L., Fužinac-Smojver, A., Muhvić, D. and Giacometti, J., "The role of polyphenols on bone metabolism in osteoporosis', Food Res. Int., 77: 290-298, (2015).

[6] Fraga, C.G., Plant phenolics and human health : biochemistry, nutrition and pharmacologye, Wiley, (2009).

[7] De la Rosa, L.A., Alvarez-Parrilla, E. and Gonzalez-Aguilar, G.A., Fruit and vegetable phytochemicals - chemistry, nutritional value, and stability, Wiley-Blackwell, (2009).

[8] Blasco, A.J., Rogerio, M.C., González, M.C. and Escarpa, A., "Electrochemical index as a screening method to determine "total polyphenolics" in foods: A proposal", Anal. Chim. Acta, 539: 237-244, (2005).

[9] Tarola, A.M., Van de Velde, F., Salvagni, L. and Preti, R. "Determination of phenolic compounds in strawberries (fragaria ananassa duch) by high performance liquid chromatography with diode array detection", Food Anal. Methods, 6: 227-237, (2013).

[10] Bayram, B., Ozcelik, B., Schultheiss, G., Frank, J. and Rimbach, G., "A validated method for the determination of selected phenolics in olive oil using high-performance liquid chromatography with coulometric electrochemical detection and a fused-core column', Food Chem., 138: 1663-1669, (2013).

[11] Nour, V., Trandafir, I. and Cosmulescu, S. "HPLC determination of phenolic acids, flavonoids and juglone in walnut leaves", J. Chromatogr. Sci., 51: 883-890, (2013).

[12] John, Y., Bowman, P.D., Kerwin, S.M. and Stavchansky, S., "Development and validation of an LCMS method to determine the pharmacokinetic profiles of caffeic acid phenethyl amide and caffeic acid phenethyl ester in male Sprague-Dawley rats", Biomed. Chromatogr., 28: 241-246, (2014).

[13] Kicel, A., Owczarek, A., Michel, P., Skalicka-Woźniak, K., Kiss, A.K. and Olszewska, M.A., "Application of HPCCC, UHPLC-PDA-ESI-MS3 and HPLC-PDA methods for rapid, one-step preparative separation and quantification of rutin in Forsythia flowers", Ind. Crops Prod., 76: 8694, (2015). 
[14] Bourget, P., Amin, A., Vidal, F., Merlette, C. and Lagarce, F., "Comparison of raman spectroscopy vs. high performance liquid chromatography for quality control of complex therapeutic objects: Model of elastomeric portable pumps filled with a fluorouracil solution', J. Pharm. Biomed. Anal., 91: 176-184, (2014).

[15] Kilmartin, P.A. and Hsu, C.F., "Characterization of polyphenols in green, oolong, and black teas, and in coffee, using cyclic voltammetry", Food Chem., 82: 501-512, (2003).

[16] Barroso, M.F., Delerue-Matos, C. and Oliveira, M.B.P.P., "Electrochemical evaluation of total antioxidant capacity of beverages using a purine-biosensor", Food Chem., 132: 1055-1062, (2012).

[17] Głód, B.K., Kiersztyn, I. and Piszcz, P. "Total antioxidant potential assay with cyclic voltammetry and/or differential pulse voltammetry measurements', J. Electroanal. Chem., 719: 24-29, (2014).

[18] Menezes Peixoto, C.R. de, Fraga, S., Rosa Justim, J. da, Silva Gomes, M., Gonçalves Carvalho, D., Jarenkow, J.A. and Fernandes de Moura, N., "Voltammetric determination of total antioxidant capacity of Bunchosia glandulifera tree extracts", J. Electroanal. Chem., 799: 519-524, (2017).

[19] David, I.G., Bizgan, A-M.C., Popa, D.E., Buleandra, M., Moldovan, Z., Badea, I.A., Tekiner, T.A., Basaga, H. and Ciucu, A.A., "Rapid determination of total polyphenolic content in tea samples based on caffeic acid voltammetric behaviour on a disposable graphite electrode", Food Chem., 173: 10591065, (2015).

[20] Demir, E. and İnam, R., "Square wave voltammetric determination of fomesafen herbicide using modified nanostructure carbon paste electrode as a sensor and application to food samples", Food Anal. Methods, 10: 74-82, (2017).

[21] Demir, E., Inam, R., Ozkan, S.A. and Uslu, B., "Electrochemical behavior of tadalafil on TiO2 nanoparticles-MWCNT composite paste electrode and its determination in pharmaceutical dosage forms and human serum samples using adsorptive stripping square wave voltammetry', J. Solid State Electrochem., 18: 2709-2720, (2014).

[22] Ginja, T.J., Alfredina, V., Barrocas, D.C. and Martins, T.D., "Electroanalytical Study of Macluraxanthone: A Natural Product with a Strong Antioxidant and Antimalarial Activity", Electroanalysis, 29: 2062-2070, (2017).

[23] Sanger, K., Zór, K., Jendresen, C.B., Heiskanen, A., Amato, L., Nielsen A.T. and Boisen, A., “'Labon-a-disc platform for screening of genetically modified E. colicells via cell-free electrochemical detection of p-coumaric acid', Sens. Actuators B Chem., 253: 999-1005, (2017).

[24] Balasundram, N., Sundram, K. and Samman, S., "Phenolic compounds in plants and agri-industrial by-products: Antioxidant activity, occurrence, and potential uses", Food Chem., 99: 191-203, (2006).

[25] Oksana, S., Marian, B., Mahendra, R. and Bo, S.H., "Plant phenolic compounds for food, pharmaceutical and cosmetics production', J. Med. Plant. Res., 6: 2526-2539 (2012).

[26] Boz, H., "p-Coumaric acid in cereals: presence, antioxidant and antimicrobial effects", Int. J. Food Sci. Technol., 50: 2323-2328, (2015).

[27] Dai, J. and Mumper, R.J., "Plant phenolic: extraction, analysis and their antioxidant and anticancer properties'', Molecules, 15: 7313-7352, (2010).

[28] Khoddami, A., Wilkes M.A. and Roberts, T.H., "Techniques for analysis of plant phenolic compounds", Molecules, 18: 2328-2375, (2013). 
[29] Bavol, D., Dejmkova, H., Scampicchio, M., Zima, J. and Barek, J., "Combination of flow injection analysis and fast scan differential pulse voltammetry for the determination of antioxidants", Electroanalysis, 29: 182-187, (2016).

[30] Masek, A., Chrzescijanska, E. and Latos, M., "Determination of antioxidant activity of caffeic acid and pcoumaric acid by using electrochemical and spectrophotometric assays", Int. J. Electrochem. Sci., 11: 10644 - 10658, (2016).

[31] Ziyatdinova, G.K., Ziganshina, E.R., Cong, P.N. and Budnikov, H.C., "Determination of the Antioxidant capacity of the micellar extracts of spices in Brij ${ }^{\circledR} 35$ medium by differential pulse voltammetry", J. Anal. Chem., 71: 573-580, (2016).

[32] Ferreira, L.M., de Souza, F.D., Aguilera, F.J.N. and Vieira I.C., "Electrochemical sensor based on rhodium nanoparticles stabilized in zwitterionic surfactant for p-coumaric acid analysis", Can. J. Chem., 95: 113-119, (2017).

[33] Kumar, A.A., Kumara Swamy, B.E., Rani, T.S., Ganesh, P.S. and Raj, Y.P., "Voltammetric determination of catechol and hydroquinone at poly(murexide) modified glassy carbon electrode", Mater. Sci. Eng. C Mater. Biol. Appl., 98: 746-752, (2019).

[34] Fajardo, A., Tapia, D., Pizarro, J., Segura, R. and Jara, P., "Determination of norepinephrine using a glassy carbon electrode modified with graphene quantum dots and gold nanoparticles by square wave stripping voltammetry', J. Appl. Electrochem., 49: 423-432, (2019).

[35] Devi, C.L. and Narayanan, S.S., "Poly(amido amine) dendrimer and silver nanoparticle-multiwalled carbon nanotubes composite with poly(neutral red)-modified electrode for the determination of ascorbic acid'’ B. Mater. Sci., 42: 73-84; (2019).

[36] Chatterjee, T.N., Das, D., Roy, R.B., Tudu, B., Hazarika, A.K., Sabhapondit, S., Tamuly, P. and Bandyopadhyay, R., "Development of a nickel hydroxide nanopetal decorated molecular imprinted polymer based electrode for sensitive detection of epigallocatechin-3-gallate in green tea', Sens. Actuators B Chem., 283: 15, 69-78, (2019).

[37] Laviron, E., Roullier, L., and Degrand, C., "A multilayer model for the study of space distributed redox modified electrodes: Part II. Theory and application of linear potential sweep voltammetry for a simple reaction"', J. Electroanal. Chem. Interfacial Electrochem., 112: 1-23, (1980).

[38] Miller, J.C. and Miller, J.N., Statistics for analytical chemistry', 2nd edn. John Wiley and Sons, New York (1988).

[39] Liu, K., Yan, L., Yao, G. and Guo, X., "Estimation of p-coumaric acid as metabolite of E-6-O-pcoumaroyl scandoside methyl ester in rat plasma by HPLC and its application to a pharmacokinetic study", J. Chromatogr. B, 831: 303-306, (2006).

[40] Zhang, L., Li, Y., Liang, Y., Liang, K., Zhang, F., Xu, T., Wang, M., Song, H., Liu, X. and Lu, B., "Determination of phenolic acid profiles by HPLC-MS in vegetables commonly consumed in China" Food Chem., 276: 538-546, (2019).

[41] Karthikeyan, R., Devadasu, C. and Babu, P.S., "Isolation, characterization, and RP-HPLC estimation of p-coumaric acid from methanolic extract of durva grass (Cynodon dactylon Linn.)", Int. J. Anal. Chem., 2015: 1-7, (2015). 
[42] Laviron, E., "General expression of the linear potential sweep voltammogram in the case of diffusionless electrochemical systems", J. Electroanal. Chem. Interfacial. Electrochem., 101: 19-28, (1979).

[43] Janeiro, P., Novak, I., Seruga, M. and Oliveira-Brett, A.M., "Electroanalytical oxidation of pcoumaric acid', Anal. Lett., 40: 3309-3321, (2007). 